\title{
A Novel Ancient Coin-Like Fractal Multiband Antenna for Wireless Applications
}

\author{
Zhen Yu, ${ }^{1,2,3}$ Jianguo Yu, ${ }^{1,2}$ Xiaoying Ran, ${ }^{3}$ and Chenhua $\mathrm{Zhu}^{3}$ \\ ${ }^{1}$ School of Electronic Engineering, Beijing University of Posts and Telecommunications, Beijing 100876, China \\ ${ }^{2}$ Beijing Key Laboratory of Work Safety Intelligent Monitoring, Beijing 100876, China \\ ${ }^{3}$ North China Institute of Science and Technology, Langfang 101601, China
}

Correspondence should be addressed to Zhen Yu; yzyuzhen@ncist.edu.cn

Received 2 January 2017; Revised 20 March 2017; Accepted 18 April 2017; Published 5 June 2017

Academic Editor: Jaume Anguera

Copyright (C) 2017 Zhen Yu et al. This is an open access article distributed under the Creative Commons Attribution License, which permits unrestricted use, distribution, and reproduction in any medium, provided the original work is properly cited.

\begin{abstract}
This study proposes a novel square-circle structure fractal multibroadband planar antenna, similar to an ancient Chinese coin-like structure, for second generation (2G), third generation (3G), fourth generation (4G), WLAN, and navigation wireless applications. The device is based on the principles and structural features of conventional monopole antenna elements, combined with the advantages of microstrip antennas and fractal geometry. A fractal method was presented for circular nested square slotted structures, similar to an ancient Chinese copper coin. The proposed antenna adapted five iterations on a fractal structure radiator, which covers more than ten mobile applications in three broad frequency bands with a bandwidth of $70 \%(1.43-2.97 \mathrm{GHz})$ for DCS1800, TD-SCDMA, WCDMA, CDMA2000, LTE33-41, Bluetooth, GPS (Global Positioning System), BDS (BeiDou Navigation Satellite System), GLONSS (Global Navigation Satellite System), GALILEO (Galileo Satellite Navigation System), and WLAN frequency bands, $16.32 \%(3.32-3.91 \mathrm{GHz})$ for LTE42, LTE43, and WiMAX frequency bands, and 10.92\% (4.85-5.41 GHz) for WLAN frequency band. The proposed antenna was fabricated on a $1.6 \mathrm{~mm}$ thick G10/FR4 substrate with a dielectric constant of 4.4 and a size of $88.5 \times 60 \mathrm{~mm}^{2}$. The measurement results reveal that the omnidirectional radiation patterns achieve a gain of $1.16-3.75 \mathrm{dBi}$ and an efficiency of $40-72 \%$. The good agreement between the measurement results and simulation validates the proposed design approach and satisfies the requirements for various wireless applications.
\end{abstract}

\section{Introduction}

With the rapid development of mobile communication systems, miniaturized multiband planar antennas have been widely used in wireless mobile handsets due to their numerous advantages, including low mass, low profile, low cost, high manufacturing precision, ease of loading, and ease of integration. In recent years, multiband and miniaturized antennas have been widely researched for use in mobile terminal devices. However, it is difficult to achieve multiband applications and miniaturization using the traditional monopole and dipole antennas in mobile terminals due to the resonance of the antenna, which has an inherently narrow bandwidth $[1,2]$.

Many technologies have been studied to realize multiband capabilities, including coupling feed technologies [35], slot loaded technologies [6,7], loading the matching network [8], loading printed distributed inductance technologies [9], and fractal technologies [10]. Three design approaches have been adopted to control the current path and resonant mode on the radiators. The first approach is to use multiple monopole or dipole antennas as the direct resonance branches with different operating frequencies to create multiple operating bands. The coupling branches or parasitic patches are isolated from the antenna [11], and the electromagnetic coupling between them is used to achieve multiband capabilities. Slots are etched on the radiator to change the local current mode and produce different resonance frequencies [12].

For miniaturization, approaches focusing on bending and folding on the radiator structure are often adopted to increase the antenna electrical length, causing the antenna to operate at lower frequencies [13]. Fractal structure design approaches are known for their compact size, low profile, and 
multiband response, with fractal space filling used to increase the antenna electrical length and radiation efficiency $[14,15]$. Furthermore, the size of the dielectric resonance antenna (DRA) is proportional to the parameters $\lambda / \varepsilon_{r}{ }^{1 / 2}$. The relative dielectric constant of the media is increased to effectively reduce the antenna size [16].

In [17], a review of electromagnetic features of microstrip antennas using fractal geometries is presented divided in four main areas: multifrequency antennas, high-directivity patches, combination of multifrequency with broadband techniques, and arrays with microstrip elements operating in localized modes. In [18], a two-layer microstrip antenna with novel square and Giuseppe Peano fractal geometries covering the GPS $(1.575 \mathrm{GHz})$, HiperLAN2 $(2.12-2.32 \mathrm{GHz})$, IEEE $802.11 \mathrm{~b} / \mathrm{g}(2.4-2.484 \mathrm{GHz})$, and WLAN and IMT $(4.6-5.2 \mathrm{GHz})$ bands is proposed. In [19], a novel Koch-like fractal curve is proposed to transform an ultrawideband (UWB) bow-tie into a so-called Koch-like sided fractal bow-tie dipole. A small isosceles triangle is cut from the centre of each side of the initial isosceles triangle. After this, the procedure iterates along the sides, similarly to a Koch curve, forming a Koch-like fractal bow-tie geometry, which operates in the multiband mode with moderate gain $(3.5-7 \mathrm{dBi})$ and high efficiency $(60-80 \%)$ to act as a candidate for such applications as PCS, WLAN, Wi-Fi, and WiMAX. In [20], a printed fractal monopole such as the Sierpinski-Carpet (SC) antenna with grounded coplanar waveguides (GCPWs) which matches throughout the $4.65-10.5 \mathrm{GHz}$ range with low cross-polar fields and a well-behaved pattern is introduced. In [21], the authors propose a fractal geometry antenna to achieve the desired miniaturization and multiband performance. Furthermore, use of a new hybrid dielectric resonator antenna (DRA) excited by a new fractal monopole antenna provides a large bandwidth range.

This paper presents a novel five-iteration square-circle structure fractal multibroadband planar antenna with a shape similar to an ancient Chinese copper coin with a circular nested square slotted for a multibroadband mobile terminal. The antenna covers more than ten mobile applications, including the DCS1800 (1,710-1,820 MHz), TDSCDMA (1,880-2,025 MHz), WCDMA (1,920-2,170 MHz), CDMA2000 (1,920-2,125 MHz), LTE33-41 (1.9-2.69 GHz), Bluetooth $(2,400-2,483.5 \mathrm{MHz})$, GPS (L1, L4), BDS (B1), GLONSS (L1), GALILEO (E1, E2), WLAN $(802.11 \mathrm{~b} / \mathrm{g} / \mathrm{n}$ : $2.4-2.48 \mathrm{GHz}$ and $802.11 \mathrm{a} / \mathrm{n}: 5.15-5.35 \mathrm{GHz})$, LTE $42 / 43$ (3.4-3.8 GHz), and WiMAX $(3.3-3.8 \mathrm{GHz})$ systems.

\section{Antenna Structure and Design Procedure}

2.1. Characteristics of the Antenna Structure. The configuration for the proposed microstrip-fed planar antenna is shown in Figure 1, and the dimensions are shown in Table 1. The antenna has a five-iteration fractal structure circular radiator nested square slot, which is similar to ancient Chinese copper coins, as shown in Figure 2, a $50 \Omega$ microstrip feed line, and a partial ground plane on the back side. The antenna is mounted on a G10/FR4 substrate with a height of $1.6 \mathrm{~mm}$, a dielectric constant $\left(\varepsilon_{r}\right)$ of 4.4 , and a loss tangent $(\delta)$ of 0.02 .
TABLE 1: Dimensions of the proposed antenna.

\begin{tabular}{lc}
\hline Dimensions parameters & Unit $(\mathrm{mm})$ \\
\hline$L$ & 88.5 \\
$L 1$ & 32.5 \\
$G$ & 2.0 \\
$H$ & 1.6 \\
$W$ & 60 \\
$W 1$ & 1 \\
$W 2$ & 2 \\
$R 1$ & 4.9 \\
$R 2$ & 7.4 \\
$R 3$ & 11.2 \\
$R 4$ & 16.5 \\
$R 5$ & 24 \\
D1 & 6.0 \\
$D 2$ & 9.1 \\
$D 3$ & 14.5 \\
D4 & 22.0 \\
D5 & 32.5 \\
\hline
\end{tabular}

The ancient coin-like fractal antenna has a basic geometry with a square slot in a circular monopole and becomes a quasi-ring antenna, as shown in Figure 3. Five iterations were performed to achieve a multiband response. The inner size increased by 0.83 times the outer size after each step-bystep iteration [11]. The step iteration of the square slot in the circular monopole is shown in Figures 3(a)-3(f).

2.2. Simulation Results. Simulations were conducted using the Ansoft High Frequency Structure Simulator (HFSS) (version 15.0) software package.

The 0th iteration fractal antenna can be regarded as monopole with a circular capacitive loading structure radiator. The gradual slot structure between the radiator and the ground produces multiresonant frequencies. The 1st iteration fractal antenna can be viewed as monopole with a ring loading structure with nested square, which leads to fiveresonant frequencies. With the improvement of the fractal order, the resonance frequencies tend to be stable and the reflection coefficients become smaller, especially for the fifth iteration fractal structure. But the antenna performance is getting worse for the sixth iteration fractal antenna, as shown in Figure 4.

Figure 5 shows that the proposed antenna operates at three different wide frequency bands with four resonance frequencies centred at $1.6 \mathrm{GHz}$ with a $-17.8 \mathrm{~dB}$ return loss, $2.6 \mathrm{GHz}$ with a $-27.6 \mathrm{~dB}$ return loss, $3.7 \mathrm{GHz}$ with a $-22.3 \mathrm{~dB}$ return loss, and $5.3 \mathrm{GHz}$ with a $-20.7 \mathrm{~dB}$ return loss. The simulated $-10 \mathrm{~dB}$ return loss bandwidth is $66.04 \%$ for the first frequency band $(1.43-2.84 \mathrm{GHz}), 16.85 \%$ for the second band $(3.37-3.99 \mathrm{GHz})$, and $20.32 \%$ for the third band (4.51-5.53 GHz). These bands cover several commercial application bands for the 2G, 3G, 4G-LTE, Wi-Fi, Bluetooth, and satellite navigation system technologies (see Table 2). 


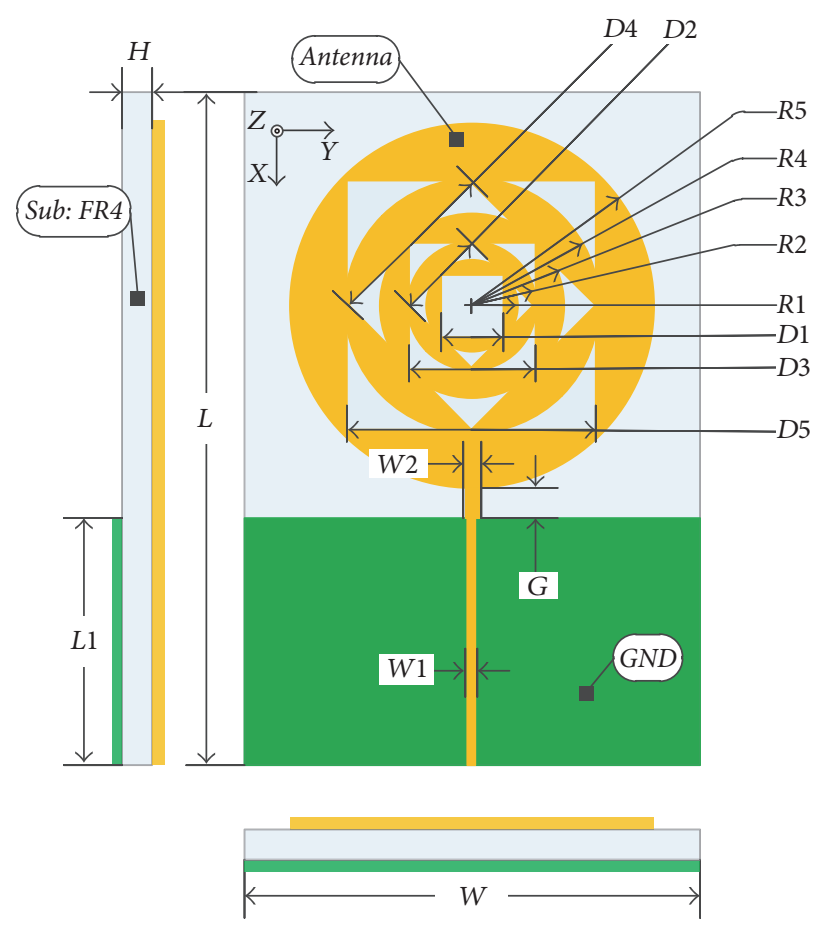

Figure 1: Layout of the proposed antenna.

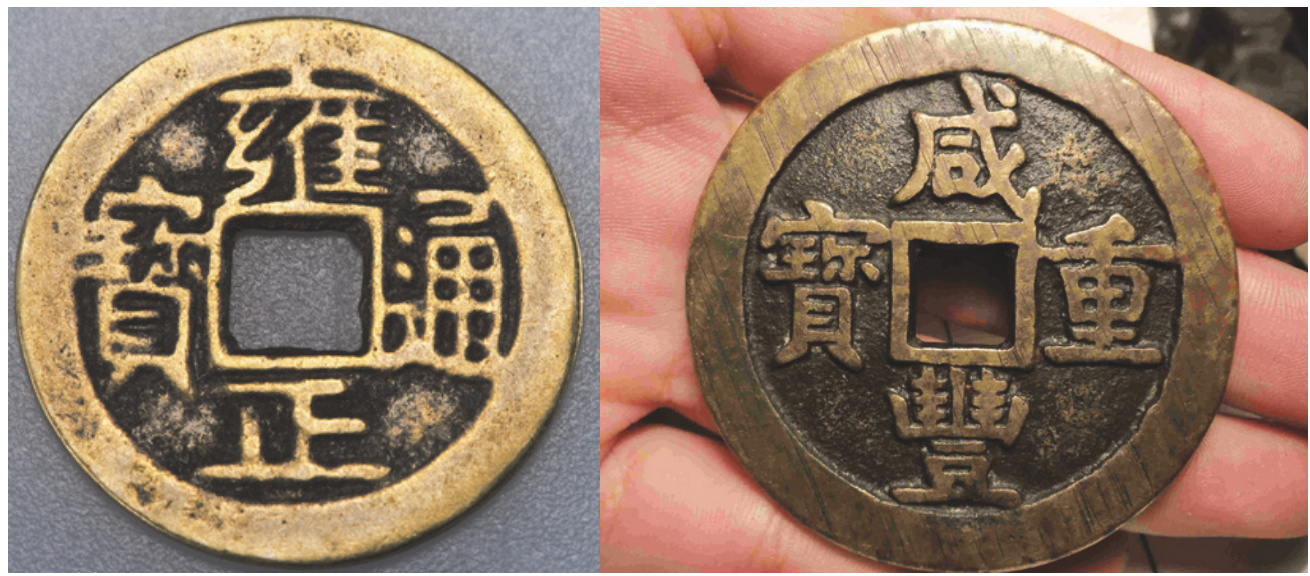

Figure 2: Photographs of ancient Chinese copper coins.

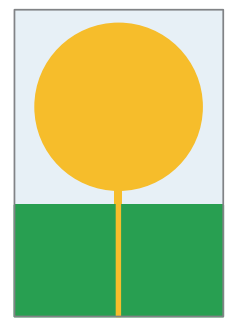

(a)

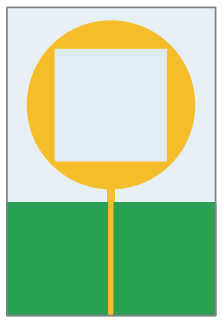

(b)

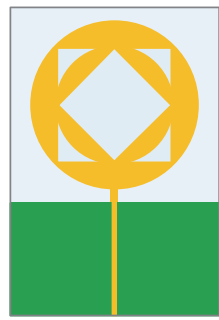

(c)

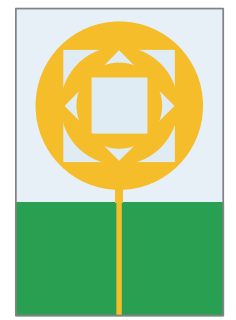

(d)

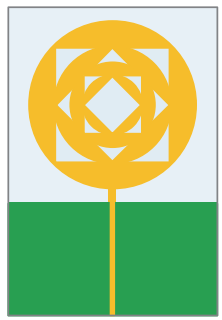

(e)

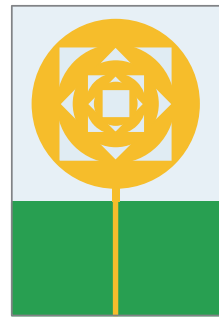

(f)

FIGURE 3: Proposed antenna in the stepwise iteration stages: (a) 0th iteration, (b) 1st iteration, (c) 2nd iteration, (d) 3rd iteration, (e) 4th iteration, and (f) 5th iteration. 


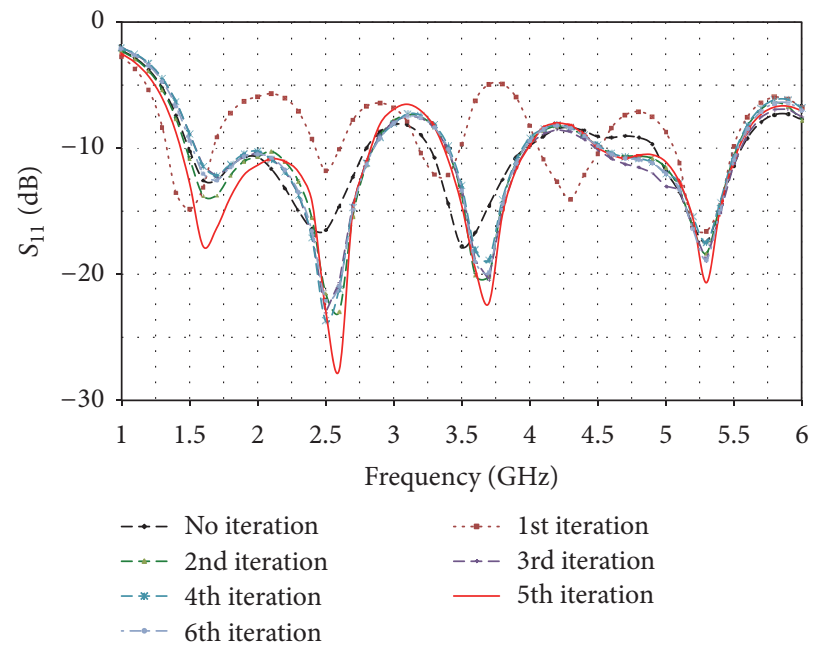

FIGURE 4: Combined simulated return loss for the antenna iterations.

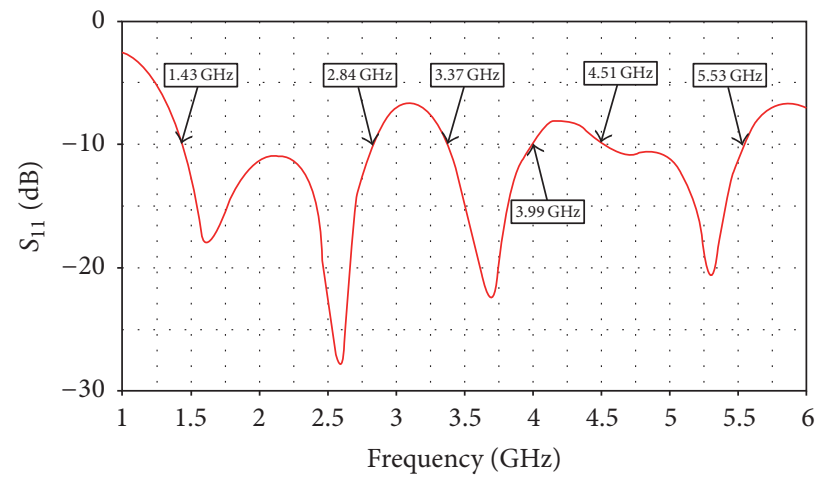

FIGURE 5: Final simulated return loss for the proposed antenna.
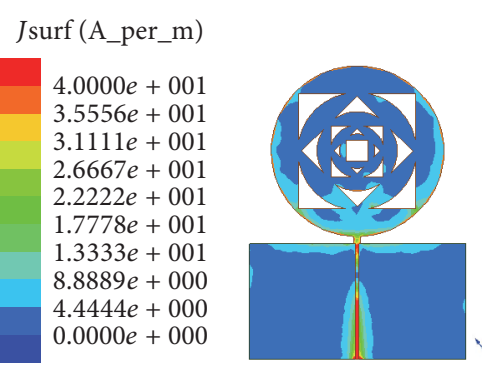

(a)

Jsurf (A_per_m)

$4.0000 e+001$ $3.5556 e+001$ $3.1111 e+001$ $2.6667 e+001$ $2.2222 e+001$ $1.7778 e+001$ $1.3333 e+001$ $8.8889 e+000$ $4.4444 e+000$ $0.0000 e+000$

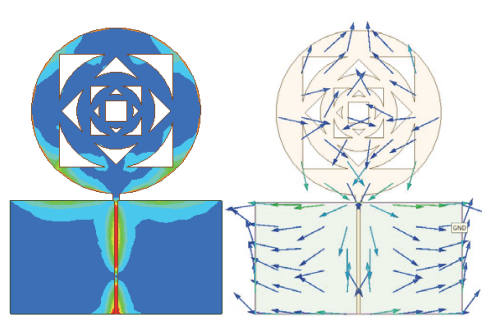

(c)
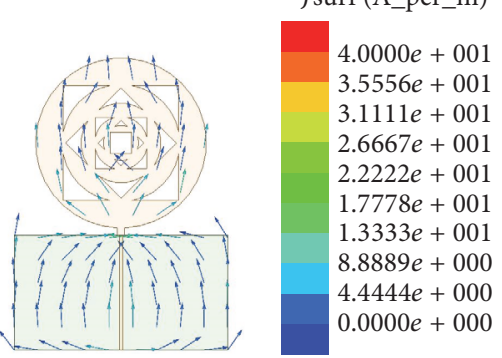

Jsurf (A_per_m)

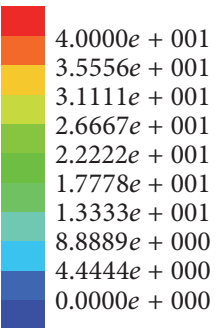

$0.0000 e+000$
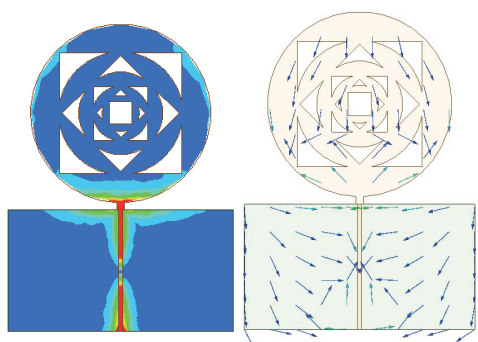

(b)
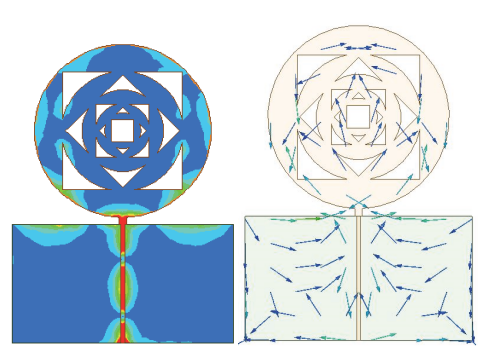

(d)

FIGURE 6: Current amplitude and vector distribution of the antenna at (a) $1.6 \mathrm{GHz}$, (b) $2.6 \mathrm{GHz}$, (c) $3.7 \mathrm{GHz}$, and (d) $5.3 \mathrm{GHz}$. 
(dB) (GainTotal) $2.5852 e+000$ $1.2547 e-001$ $-2.3342 e+000$ $-2.3342 e+000$ $-4.7940 e+000$ $-7.2537 e+000$ $-9.7134 e+000$ $-1.2173 e+001$ $-1.4633 e+001$ $-1.7093 e+001$ $-1.9552 e+001$ $-2.2012 e+001$ $-2.4472 e+001$ $-2.6931 e+001$ $-2.9391 e+001$ $-3.1851 e+001$ $-3.4310 e+001$ $-3.4310 e+001$

(dB) (GainTotal)
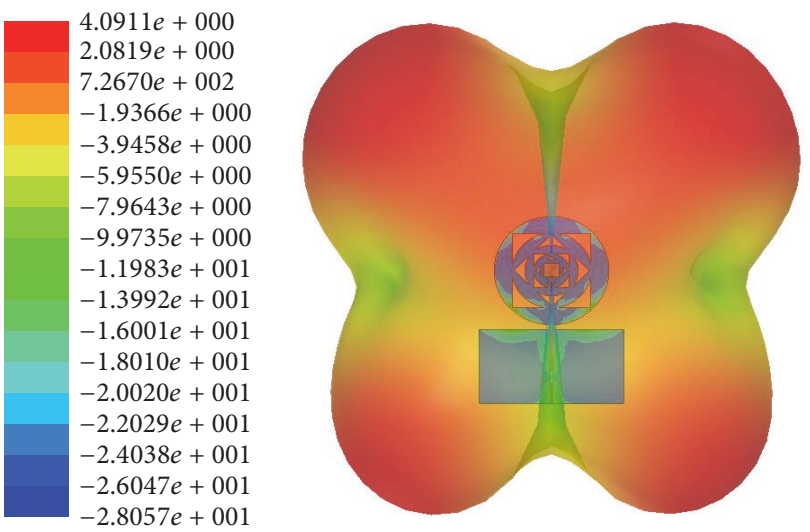

(c)

(a)
(dB) (GainTotal) $3.5924 e+000$ $1.1384 e+000$ $-1.3156 e+000$ $-3.7696 e+000$ $-6.2236 e+000$ $-8.6775 e+000$ $-1.1132 e+001$ $-1.3586 e+001$ $-1.6039 e+001$ $-1.8493 e+001$ $-2.0947 e+001$ $-2.3401 e+001$ $-2.5855 e+001$ $-2.8309 e+001$ $-3.0763 e+001$ $-3.3217 e+001$ $-3.5671 e+001$

(dB) (GainTotal) $5.6102 e+000$ $3.1826 e+000$ $7.5512 e-001$ $-1.6724 e+000$ $-4.0999 e+000$ $-6.5274 e+000$

$-8.9550 e+000$ $-1.1382 e+001$

$-1.3810 e+001$

$-1.6238 e+001$

$-1.8665 e+001$

$-2.1093 e+001$

$-2.3520 e+001$

$-2.5948 e+001$

$-2.8375 e+001$

$-3.0803 e+001$

$-3.3230 e+001$

FIGURE 7: 3D radiation patterns at (a) $1.6 \mathrm{GHz}$, (b) $2.6 \mathrm{GHz}$, (c) $3.7 \mathrm{GHz}$, and (d) $5.3 \mathrm{GHz}$.

TABLE 2: Frequency bands covered by the antenna.

\begin{tabular}{lcc}
\hline Band number & Bandwidth & Covered commercial bands \\
\hline & & DCS1800 (1,710-1,820 MHz), TD-SCDMA (1,880-2,025 MHz, \\
& & $2,300-2,400 \mathrm{MHz}$ supplementary), WCDMA (1,920-2,170 MHz, \\
1 & $(66.04 \%)$ & $1,755-1,880 \mathrm{MHz}$ supplementary), CDMA2000(1,920-2,125 MHz), \\
& LTE33-41 (1,900-2,690 MHz), Bluetooth (2,400-2,483.5 MHz), \\
& & GPS (L1, L4), BDS (B1), GLONSS (L1), GALILEO (E1, E2), WLAN \\
2 & $3.37-3.99 \mathrm{GHz}$ & $(802.11 \mathrm{~b} / \mathrm{g} / \mathrm{n}: 2.4-2.48 \mathrm{GHz})$ \\
& $(16.85 \%)$ & LTE42/43 (3.4-3.8 GHz), WiMAX (3.3-3.8 GHz) \\
& $4.51-5.53 \mathrm{GHz}$ & WLAN (802.11a/n: $5.15-5.35 \mathrm{GHz})$ \\
\hline
\end{tabular}

The surface current amplitude and vector distribution on the conducting part of the proposed antenna at centre frequencies of $1.6,2.6,3.7$, and $5.3 \mathrm{GHz}$ are shown in Figures $6(\mathrm{a})-6(\mathrm{~d})$, respectively. For the $1.6 \mathrm{GHz}$ frequency band, the outer edges of the monopole have more current (see Figure 6(a)). As the frequency increases, the current becomes more concentrated at the inner iteration surface. For the $5.3 \mathrm{GHz}$ frequency band, the current reaches a relative maximum at the edges of the radiator (see Figure 6(d)).

The simulated $3 \mathrm{D}$ gain and far-field normalized Eplane/H-plane radiation patterns of the proposed antenna at the centre frequencies of $1.6,2.6,3.7$, and $5.3 \mathrm{GHz}$ with peak gains of $2.59,3.59,4.09$, and $5.61 \mathrm{dBi}$ are shown in Figures 7 and 8, respectively. The E-plane and $\mathrm{H}$-plane patterns are 


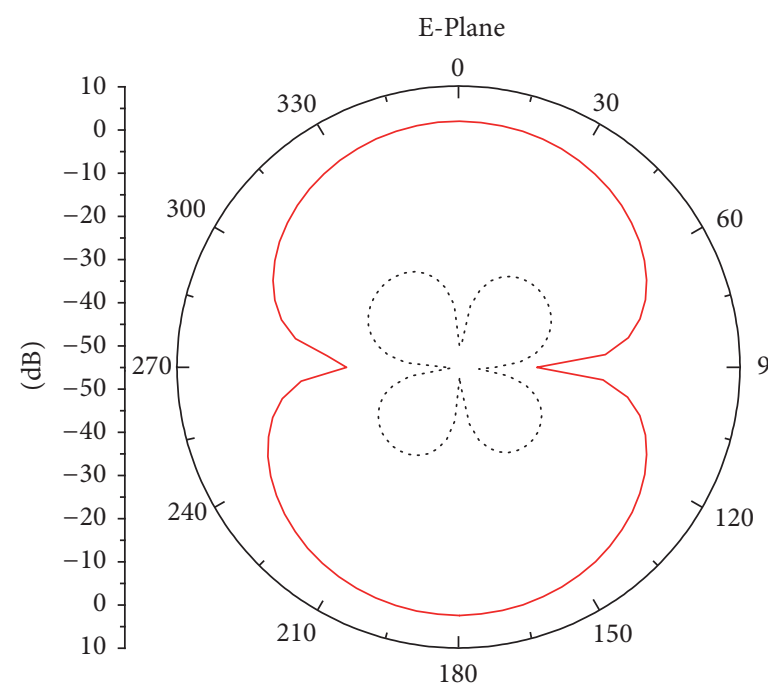

— Co-Pol

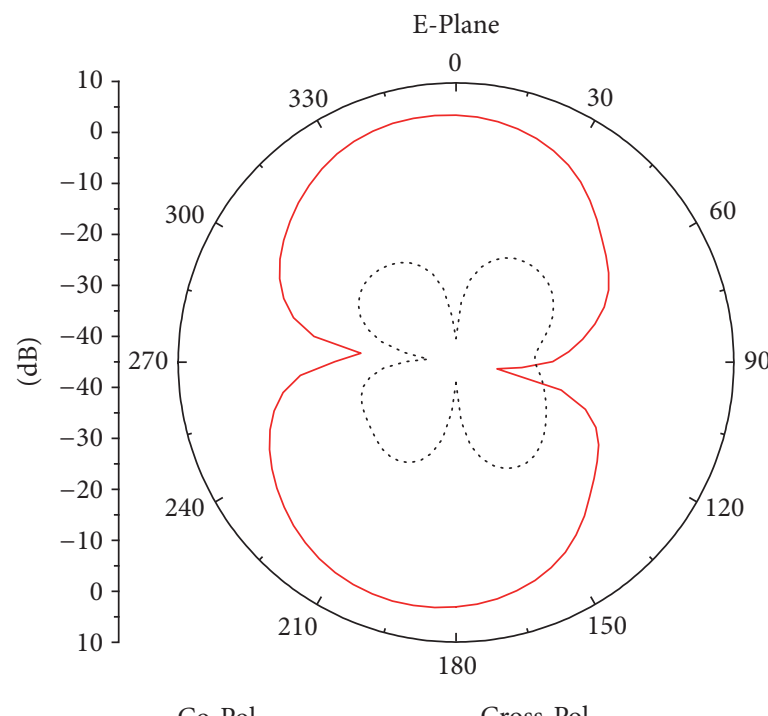

$-\mathrm{Co}-\mathrm{Pol}$

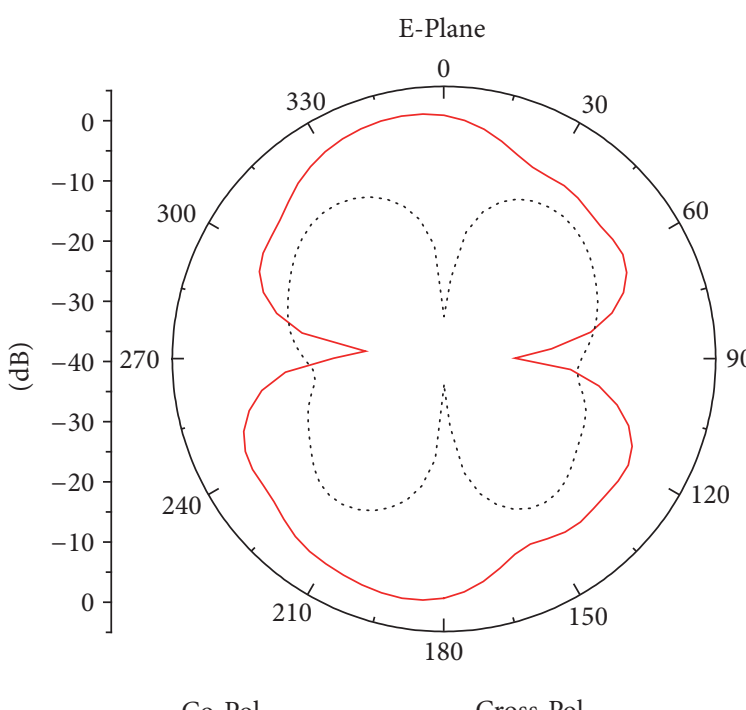

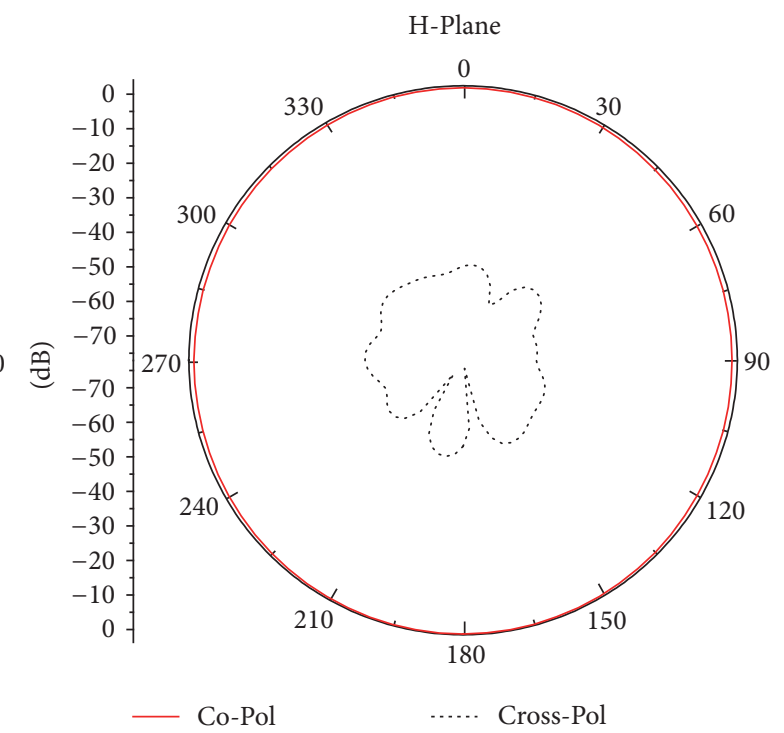

(a)

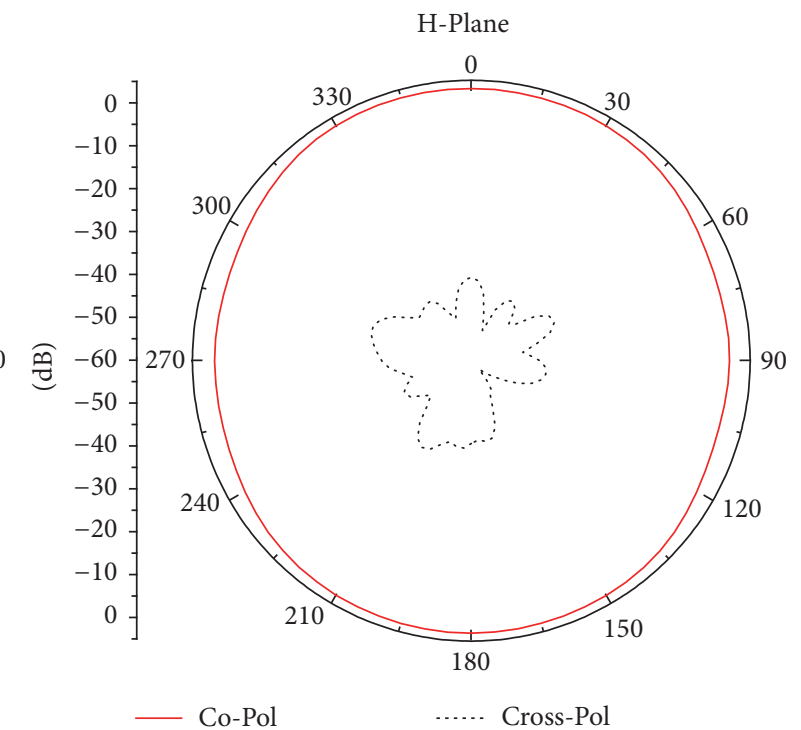

(b)

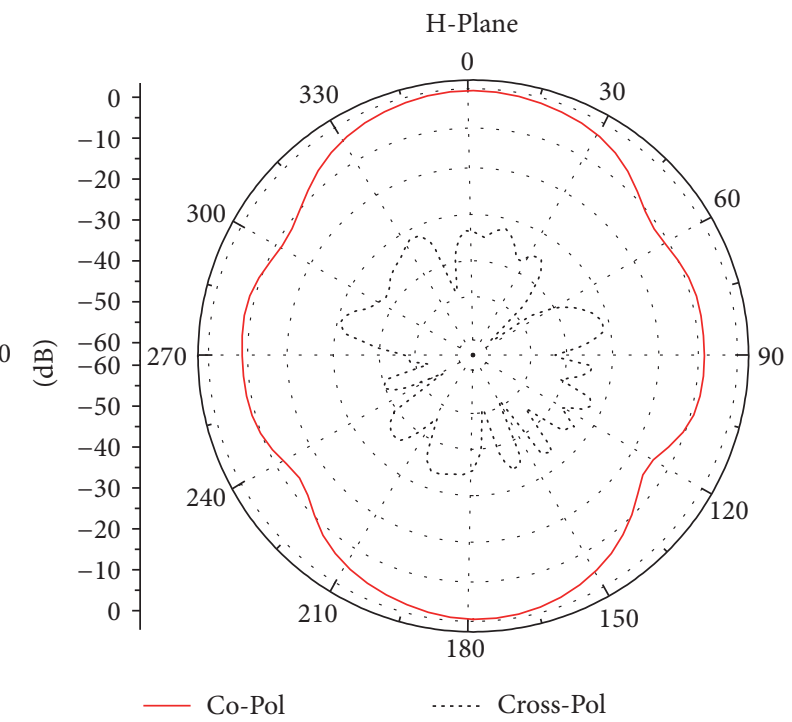

(c)

Figure 8: Continued. 

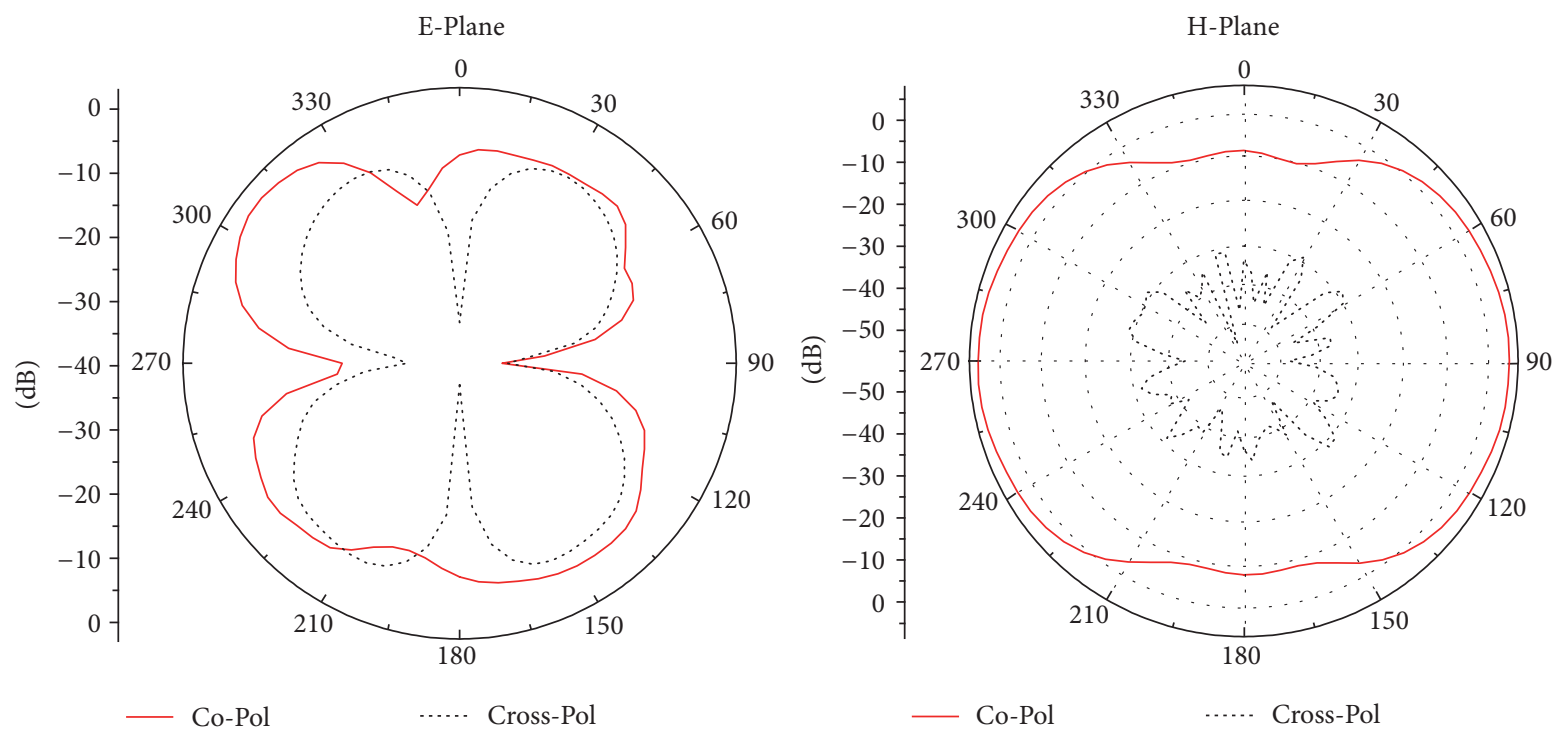

(d)

Figure 8: E-plane and H-plane radiation patterns at (a) $1.6 \mathrm{GHz}$, (b) $2.6 \mathrm{GHz}$, (c) $3.7 \mathrm{GHz}$, and (d) $5.3 \mathrm{GHz}$.

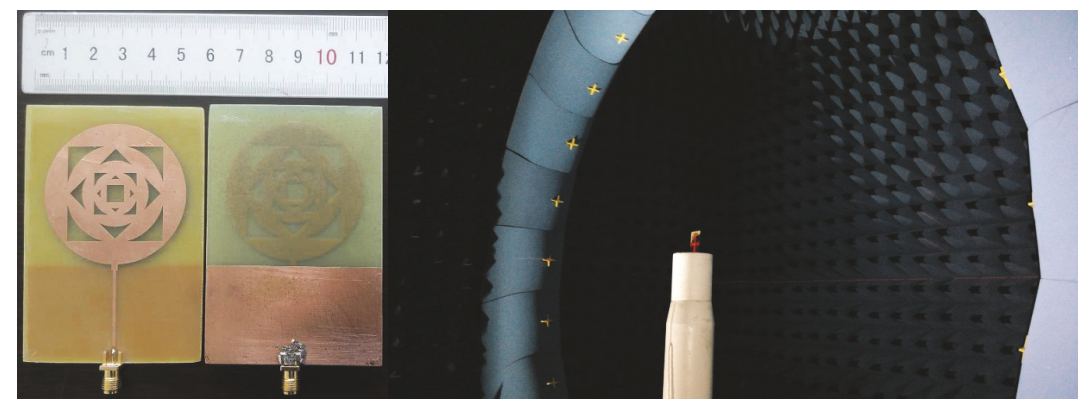

FIGURE 9: Fabricated antenna prototype and experimental test setup in an anechoic chamber.

omnidirectional at the low band and close to omnidirectional at all other bands, as the higher-order modes produce nulls and side lobes. Low level of cross-polarization is obtained.

\section{Fabrication and Measured Results}

A prototype was fabricated and measured to verify the broadband performance of the multifrequency planar antenna. The antenna was built on a $1.6 \mathrm{~mm}$ thick G10/FR4 substrate with a loss tangent of 0.02 and a $30 \mu \mathrm{m}$ thick copper layer on both sides. The front and back views of the antenna are shown in Figure 9. The antenna was tested using an SG24 Satimo antenna measurement system in an anechoic chamber and an Agilent network analyzer N5230C (see Figure 9).

The measured return loss and simulated results are compared and good agreement is observed, as shown in Figure 10. However, there exist some discrepancies that can be due to some reasons such as the implementation of the antenna precision and interface deviation. The bandwidth for a $-10 \mathrm{~dB}$ return loss covers the same mobile bands as the simulated ones, as shown in Table 3.

The measured and simulated far-field normalized Eplane/H-plane and $3 \mathrm{D}$ radiation patterns of the antenna at

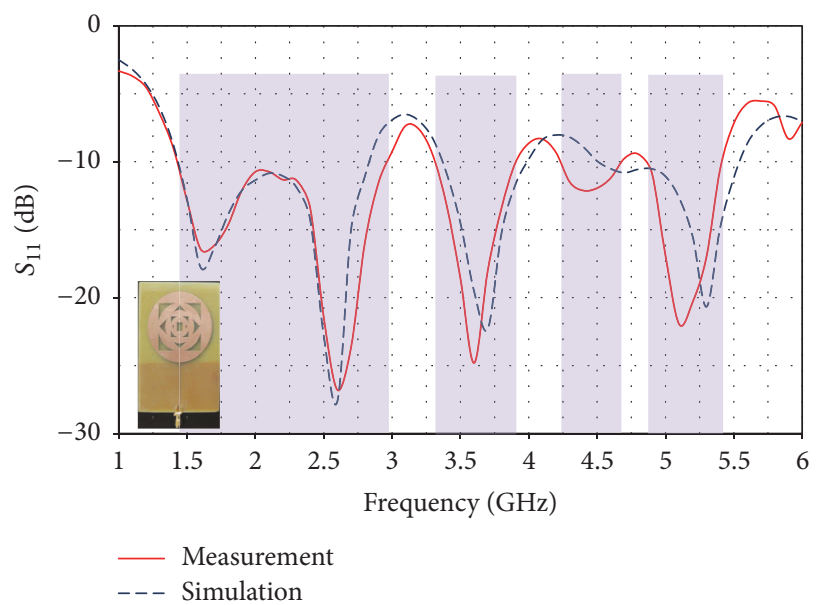

Figure 10: Measured and simulated $S_{11}$ of the antenna.

1.6, 2.6, 3.7, and $5.3 \mathrm{GHz}$ are shown in Figures 11(a)-11(d). Good agreement between the measured result and simulation predictions is achieved. The fabricated antenna has suitable 

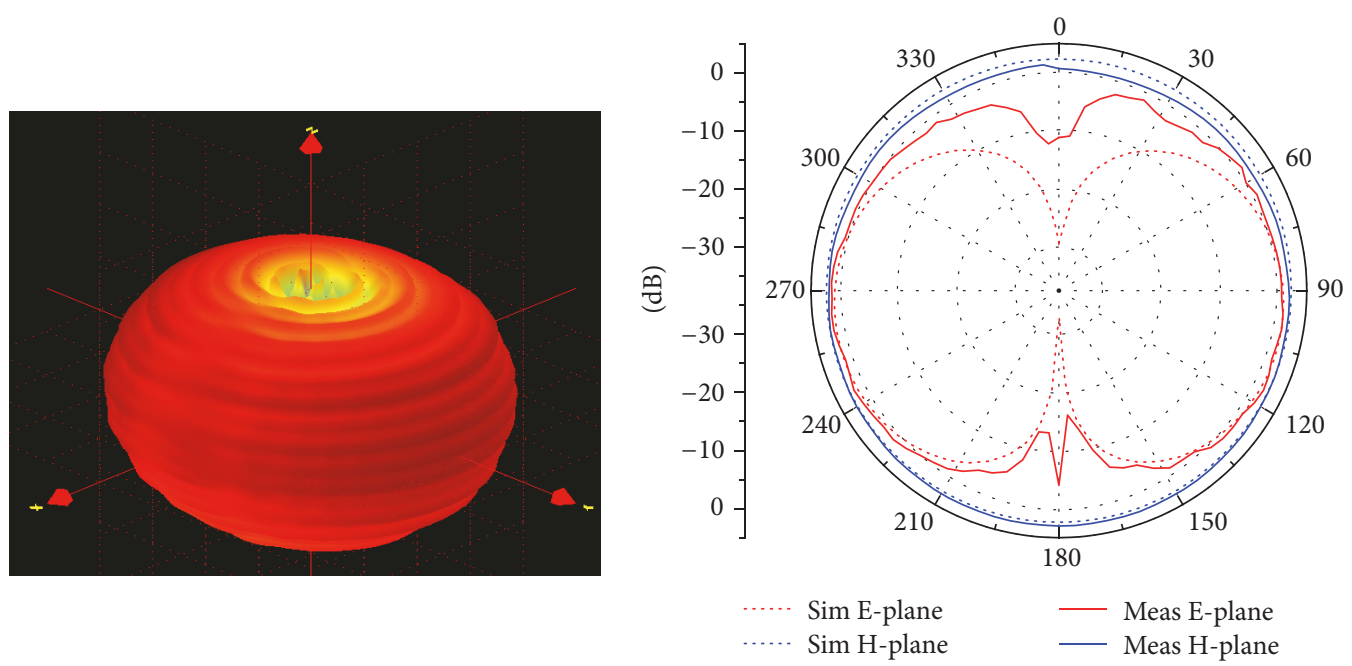

(a)
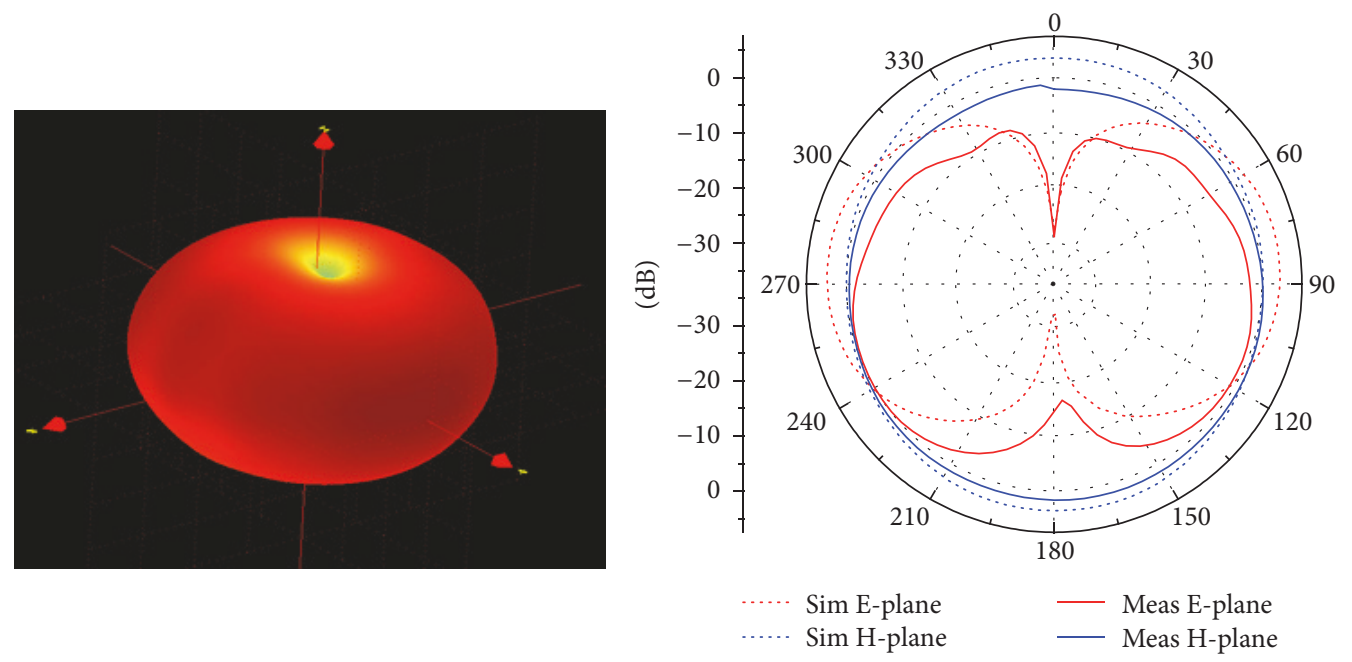

(b)
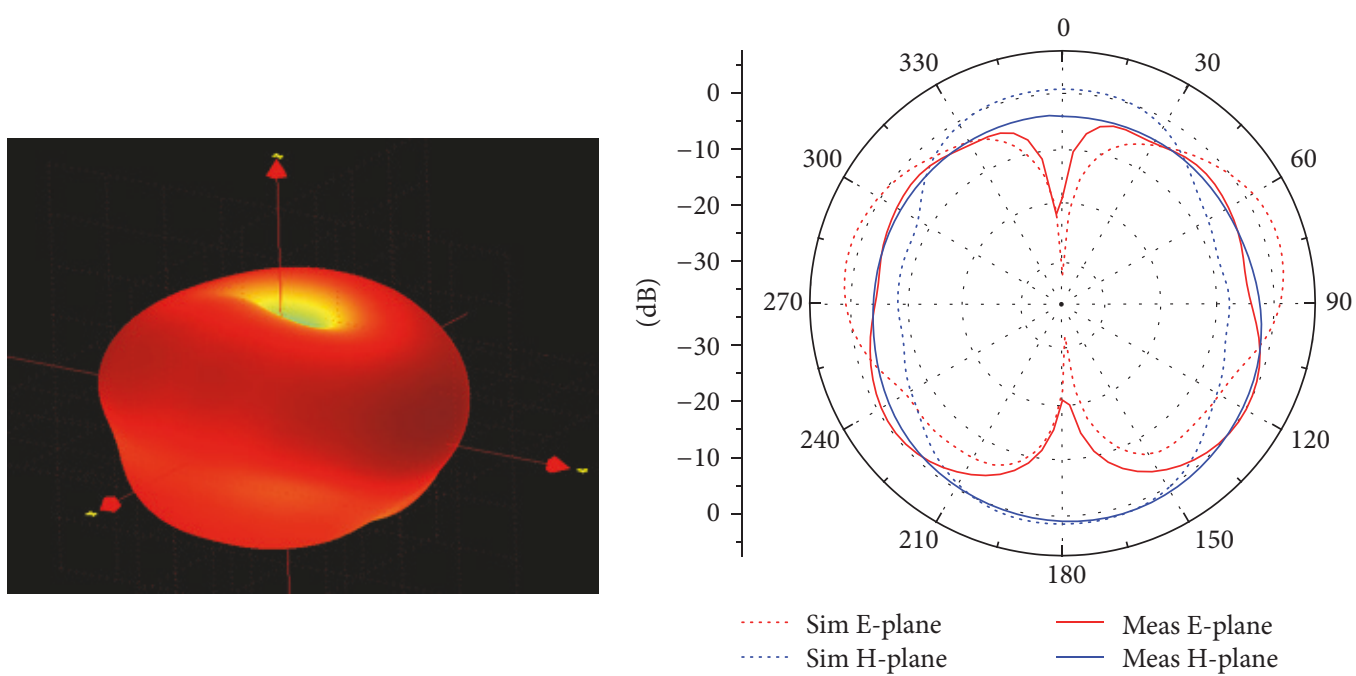

(c)

Figure 11: Continued. 

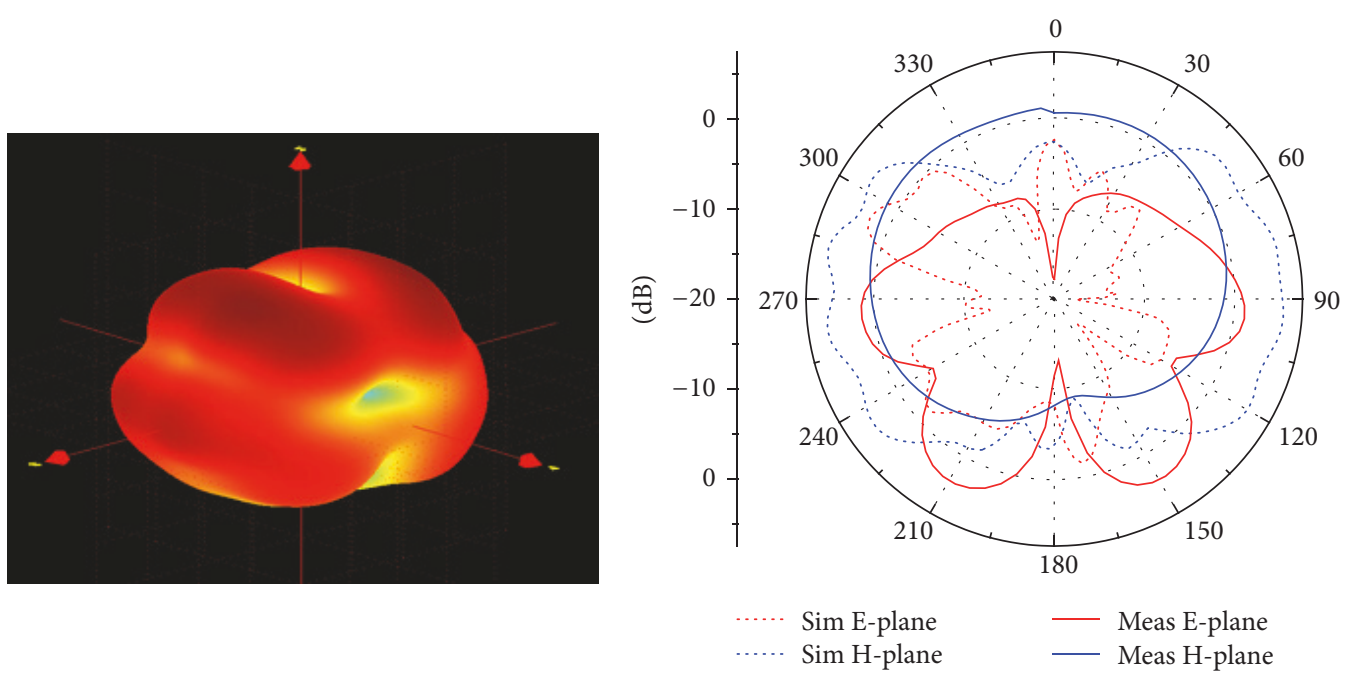

(d)

Figure 11: Measured and simulated 3D and E-plane/H-plane radiation patterns at (a) $1.6 \mathrm{GHz}$, (b) $2.6 \mathrm{GHz}$, (c) $3.7 \mathrm{GHz}$, and (d) $5.3 \mathrm{GHz}$.

TABLE 3: Measured bandwidth and frequency bands covered by the antenna.

\begin{tabular}{lcc}
\hline Band number & Bandwidth & Covered commercial bands \\
\hline & & DCS1800 (1,710-1,820 MHz), TD-SCDMA (1,880-2,025 MHz, \\
& $1.43-2.97 \mathrm{GHz}$ & $2,300-2,400 \mathrm{MHz}$ supplementary), WCDMA (1,920-2,170 MHz, \\
1 & $(70 \%)$ & $1,755-1,880 \mathrm{MHz}$ supplementary), CDMA2000 (1,920-2,125 MHz), \\
& LTE33-41 (1,900-2,690 MHz), Bluetooth (2,400-2,483.5 MHz), \\
& & GPS (L1, L4), BDS (B1), GLONSS (L1), GALILEO (E1, E2), WLAN \\
& & (802.11b/g/n: 2.4-2.48 GHz) \\
2 & $3.32-3.91 \mathrm{GHz}$ & LTE42/43 (3.4-3.8 GHz), WiMAX (3.3-3.8 GHz) \\
3 & $(16.32 \%)$ & None \\
4 & $4.22-4.68 \mathrm{GHz}$ & \\
& $(10.34 \%)$ & WLAN (802.11a/n: 5.15-5.35 GHz)
\end{tabular}

radiation at all frequency bands with omnidirectional characteristics at $\mathrm{H}$-plane. However, there exist some discrepancies that can be due to some reasons such as the implementation of the interface deviation.

The realized gain and radiation efficiency of the antenna were measured at far field in an anechoic chamber using the substitution method, as shown in Figure 12. The realized gain is approximately $1.16-3.36 \mathrm{dBi}$ for the first band, $2.1-3.5 \mathrm{dBi}$ for the second band, and $3.3-3.75 \mathrm{dBi}$ for the third band. The antenna efficiency varies between 40 and $72 \%$ over the low frequency band, is approximately $66 \%$ in the middle frequency band, and is greater than $61 \%$ in the high frequency band, which is desired for most related mobile communication applications.

\section{Conclusion}

This study developed an ancient coin-like structure fractal multibroadband planar antenna for DCS1800, CDMA, LTE,

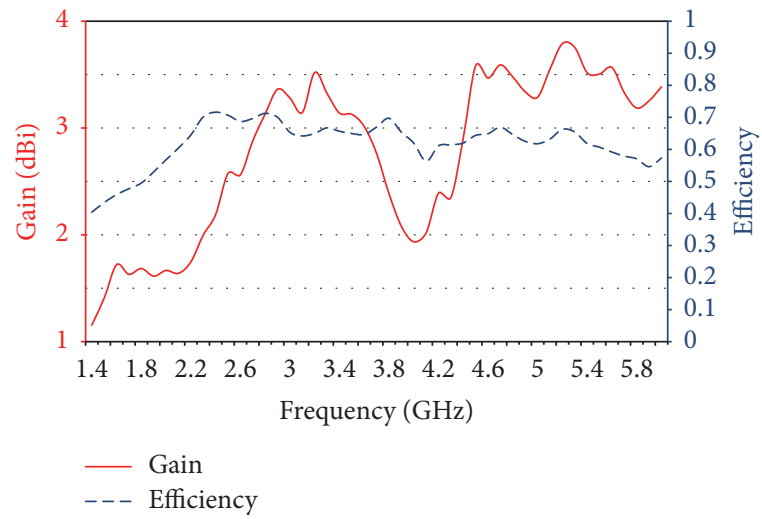

FIGURE 12: Measured gain and efficiency curves.

Bluetooth, satellite navigation system, WLAN, and WiMAX applications. The multiband antenna covers three broad 
frequency bands with a bandwidth of 70\% $(1.43-2.97 \mathrm{GHz})$ for the DCS1800, TD-SCDMA, WCDMA, CDMA2000, LTE33-41, Bluetooth, GPS, BDS, GLONSS, GALILEO, and WLAN frequency bands, $16.32 \%(3.32-3.91 \mathrm{GHz})$ for the LTE42,43 and WiMAX frequency bands, and 10,925\% $(4.85-5.41 \mathrm{GHz})$ for the WLAN frequency bands. The measured results reveal omnidirectional radiation patterns with a $1.16-3.75 \mathrm{dBi}$ gain and an efficiency of $40-72 \%$. As a result, the proposed compact and lightweight antenna possessing good radiation characteristics is considered suitable for most related wireless applications.

\section{Conflicts of Interest}

The authors declare that the mentioned funding sources do not lead to any conflicts of interest regarding the publication of this manuscript.

\section{Acknowledgments}

This work was supported in part by the National Natural Science Foundation of China under Grants 61372035 and 61531007 and the Langfang City Science and Technology Research and Development Program under Grant 2016011007.

\section{References}

[1] X. L. Sun, L. Liu, S. W. Cheung, and T. I. Yuk, "Dual-band antenna with compact radiator for $2.4 / 5.2 / 5.8 \mathrm{GHz}$ WLAN applications," IEEE Antennas and Wireless Propagation Letters, vol. 60, no. 12, pp. 5924-5931, 2012.

[2] S. Verma and P. Kumar, "Compact triple-band antenna for WiMAX and WLAN applications," Electronics Letters, vol. 50, no. 7, pp. 484-486, 2014.

[3] D.-G. Kang and Y. Sung, "Coupled-fed planar printed shorted monopole antenna for LTE/WWAN mobile handset applications," IET Microwaves, Antennas and Propagation, vol. 6, no. 9, pp. 1007-1016, 2012.

[4] Z. L. Xie, W. B. Lin, and G. L. Yang, "Coupled-fed printed antenna for LTE mobile handset applications," Microwave and Optical Technology Letters, vol. 56, no. 8, pp. 1752-1756, 2014.

[5] J.-H. Chen, Y.-L. Ban, H.-M. Yuan, and Y.-J. Wu, "Printed coupled-fed PIFA for seven-band GSM/UMTS/LTE WWAN mobile phone," Journal of Electromagnetic Waves and Applications, vol. 26, no. 2-3, pp. 390-401, 2012.

[6] Z. Chen, Y. L. Ban, J. H. Chen, J. L. W. Li, and Y. J. Wu, "Bandwidth enhancement of LTE/WWAN printed mobile phone antenna using slotted ground structure," Progress in Electromagnetics Research, vol. 129, pp. 469-483, 2012.

[7] M. T. Wu and M. L. Chuang, "Multibroadband slotted bow-tie monopole antenna," IEEE Antennas and Wireless Propagation Letters, vol. 14, pp. 887-890, 2015.

[8] Y.-L. Ban, Y.-F. Qiang, Z. Chen, K. Kang, and J. L.-W. Li, "Lowprofile narrow-frame antenna for seven-band WWAN/LTE smartphone applications," IEEE Antennas and Wireless Propagation Letters, vol. 13, pp. 463-466, 2014.

[9] C. H. Chang and K. L. Wong, "Small-size printed monopole with a printed distributed inductor for pentaband WWAN mobile phone application," Microwave and Optical Technology Letters, vol. 51, no. 12, pp. 2903-2908, 2009.
[10] C. D. L. Nóbrega, M. R. Da Silva, P. H. D. F. Silva, A. G. D’Assunção, and G. L. Siqueira, "Simple, compact, and multiband frequency selective surfaces using dissimilar sierpinski fractal elements," International Journal of Antennas and Propagation, vol. 2015, Article ID 614780, 5 pages, 2015.

[11] I. B. Issa and M. Essaaidi, "A novel compact multiband broadside-coupled split-ring-resonator metamaterial structure loaded fractal slot antenna for $4 \mathrm{G}$ communications and wireless systems," Microwave and Optical Technology Letters, vol. 58, no. 12, pp. 2823-2828, 2016.

[12] N. T. Thanh, Y. Yang, K. Y. Lee, and K. C. Hwang, "Dual circularly-polarized spidron fractal slot antenna," Electromagnetics, vol. 37, no. 1, pp. 40-48, 2017.

[13] Y. X. Guo, M. Y. W. Chia, and Z. N. Chen, "Miniature builtin multiband antennas for mobile handsets," Asian Himalayas International Conference on Internet, 2009.

[14] J. S. Khinda, M. R. Tripathy, and D. Gambhir, "Multi-edged wide-band rectangular microstrip fractal antenna array for Cand X-band wireless applications," Journal of Circuits Systems and Computers, vol. 26, no. 4, Article ID 1750068, 2017.

[15] S. Singhal, P. Singh, and A. K. Singh, "Asymmetrically CPWfed octagonal sierpinski UWB fractal antenna," Microwave and Optical Technology Letters, vol. 58, no. 7, pp. 1738-1745, 2016.

[16] R. K. Yadav, J. Kishor, and R. L. Yadava, "A Chaucer microstrip fractal antenna for mobile applications," Journal of Communications Technology and Electronics, vol. 61, no. 2, pp. 138-144, 2016.

[17] J. Anguera, C. Puente, C. Borja, and J. Soler, "Fractal-shaped antennas: a review," Wiley Encyclopedia of RF and Microwave Engineering, vol. 2, pp. 1620-1635, 2005.

[18] H. Oraizi and S. Hedayati, "Circularly polarized multiband microstrip antenna using the square and Giuseppe Peano fractals," IEEE Transactions on Antennas and Propagation, vol. 60, no. 7, pp. 3466-3470, 2012.

[19] D. Li and J.-F. Mao, "A Koch-like sided fractal bow-tie dipole antenna," IEEE Transactions on Antennas and Propagation, vol. 60, no. 5, pp. 2242-2251, 2012.

[20] M. N. Jahromi, A. Falahati, and R. M. Edwards, "Bandwidth and impedance-matching enhancement of fractal monopole antennas using compact grounded coplanar waveguide," IEEE Transactions on Antennas and Propagation, vol. 59, no. 7, pp. 2480-2487, 2011.

[21] Z.-C. Hao, X. Liu, X. Huo, and K.-k. Fan, "Planar high-gain circularly polarized element antenna for array applications," IEEE Transactions on Antennas and Propagation, vol. 63, no. 5, pp. 1937-1948, 2015. 


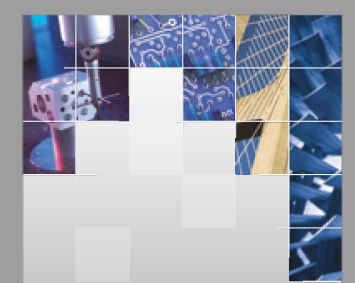

\section{Enfincering}
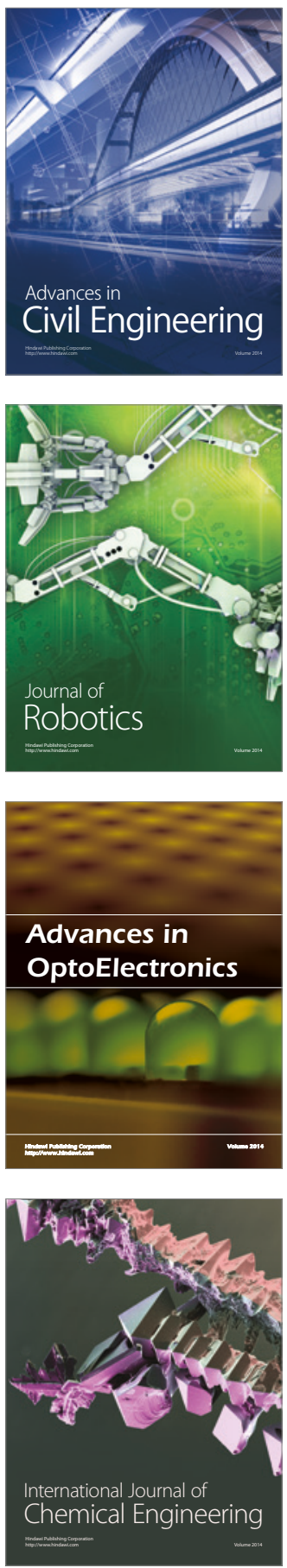

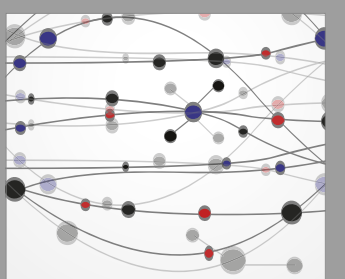

The Scientific World Journal

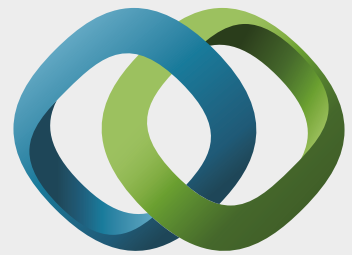

\section{Hindawi}

Submit your manuscripts at

https://www.hindawi.com
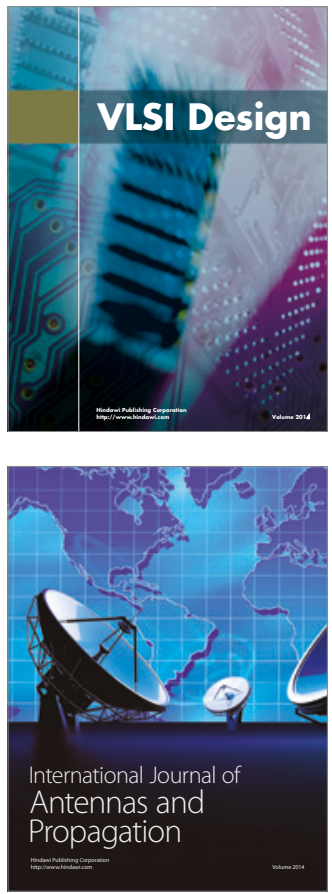

\section{Rotating}

Machinery
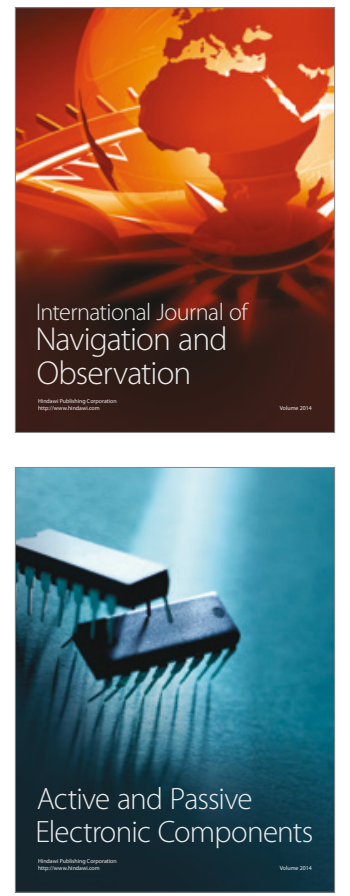
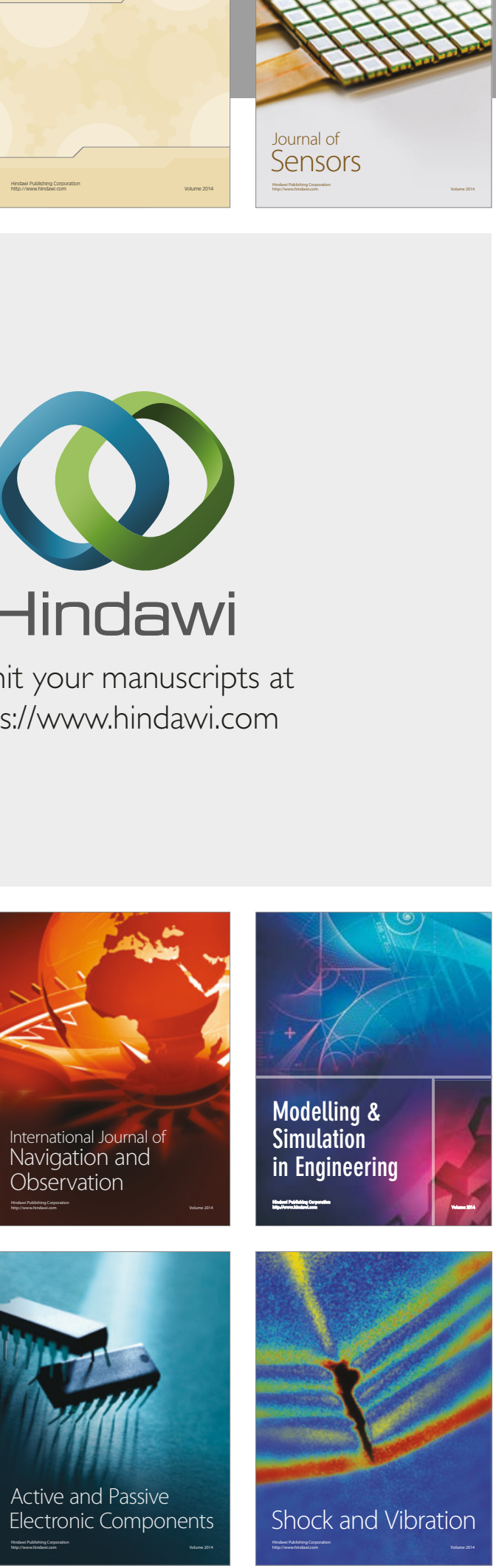
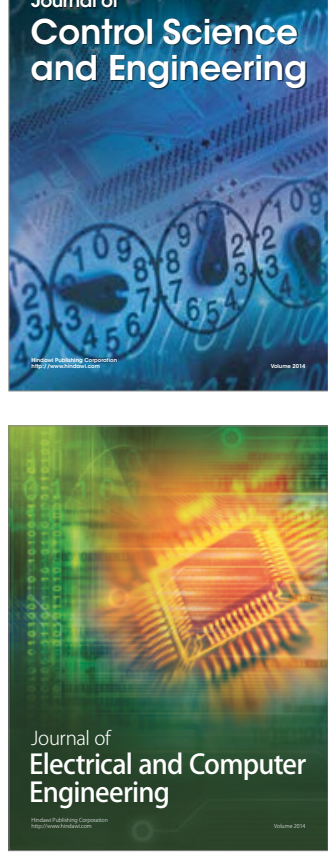

Distributed

Journal of

Control Science

and Engineering
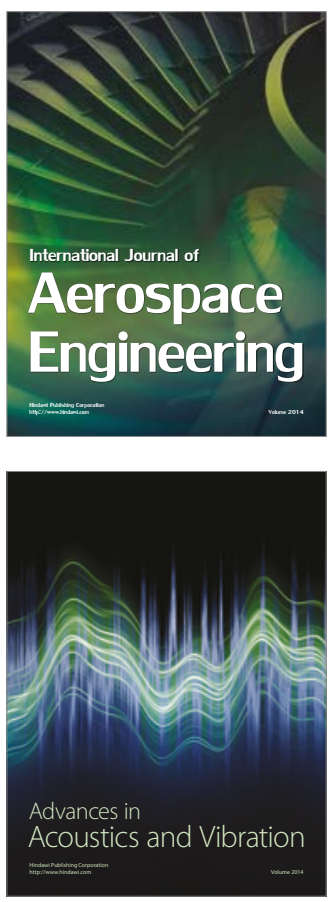

Sensor Networks 